ARTICLE

\title{
Boosting photocatalytic hydrogen production from water by photothermally induced biphase systems
}

Shaohui Guo (1) ${ }^{1}$, Xuanhua $\mathrm{Li}^{1 凶}, \mathrm{Ju} \mathrm{Li}^{2}$ \& Bingqing Wei ${ }^{3 凶}$

Solar-driven hydrogen production from water using particulate photocatalysts is considered the most economical and effective approach to produce hydrogen fuel with little environmental concern. However, the efficiency of hydrogen production from water in particulate photocatalysis systems is still low. Here, we propose an efficient biphase photocatalytic system composed of integrated photothermal-photocatalytic materials that use charred wood substrates to convert liquid water to water steam, simultaneously splitting hydrogen under light illumination without additional energy. The photothermal-photocatalytic system exhibits biphase interfaces of photothermally-generated steam/photocatalyst/hydrogen, which significantly reduce the interface barrier and drastically lower the transport resistance of the hydrogen gas by nearly two orders of magnitude. In this work, an impressive hydrogen production rate up to $220.74 \mu \mathrm{mol} \mathrm{h}^{-1} \mathrm{~cm}^{-2}$ in the particulate photocatalytic systems has been achieved based on the wood/CoO system, demonstrating that the photothermal-photocatalytic biphase system is cost-effective and greatly advantageous for practical applications.

\footnotetext{
${ }^{1}$ State Key Laboratory of Solidification Processing, Center for Nano Energy Materials, School of Materials Science and Engineering, Northwestern Polytechnical University, Xi'an, China. ${ }^{2}$ Department of Nuclear Science and Engineering, Massachusetts Institute of Technology, Cambridge, MA, USA.

${ }^{3}$ Department of Mechanical Engineering, University of Delaware, Newark, DE, USA. ${ }^{\circledR}$ email: lixh32@nwpu.edu.cn; weib@udel.edu
} 
S olar-driven hydrogen production from water is a potentially efficient way to address the environmental problems and global energy crisis of fuel production. In particular, hydrogen gas has a high energy capacity $\left(143 \mathrm{MJ} \mathrm{kg}^{-1}\right)$ and releases no toxic emissions ${ }^{1}$. Therefore, an efficient and rapid photocatalytic hydrogen-production method is urgently needed ${ }^{2,3}$. There are three main types of solar-driven hydrogen production systems: particulate photocatalysis, photovoltaic-assisted electrolysis (PV-E), and photoelectrochemical cells (PEC) ${ }^{2}$, where the particulate photocatalysis is predicted to be more cost-effective than the other two systems ${ }^{4}$. Unfortunately, the solar to hydrogen conversion efficiency in particulate photocatalysis remains low though many strategies, including structural and defect engineering, plasmonic effects, and elemental doping, have been discussed to improve photocatalysts' optical absorption and photoinduced charge separation and transport ${ }^{5-7}$.

In this work, from the phase-interface perspective, we design an efficient and cost-effective photocatalytic system composed of integrated photothermal-photocatalytic materials that can easily convert liquid water to water steam via photothermal transpiration effect with charred wood substrates. And the steam is simultaneously split into hydrogen by the photocatalysts loaded on the wood under light illumination without additional energy. The design exhibits biphase interfaces of self-generated steam/photocatalyst loaded on the charred wood substrates/hydrogen gas. Our strategy of the photothermally induced biphase interfacial feature differs from previous studies of the room-temperature vapor in moisture environment to reduce the catalysts corrosion (the humidity was realized through a complex microfluidic microreactor ${ }^{8-10}$, convection effect ${ }^{11}$, and hydrophobic effect ${ }^{12}$ ) and plasmonic thermal effects ${ }^{13}$ and nearinfrared photothermal effects ${ }^{14,15}$ in the triphase interfaces of liquid water/photocatalyst/hydrogen. This photothermal-photocatalytic biphase system kinetically lowers the hydrogen gas's transport resistance by nearly two orders of magnitude to allow the easy escape of hydrogen gas from the system. It also thermodynamically reduces the interface barrier in the adsorption process of gas-phase water molecules to photocatalysts. In this work, such a biphase system significantly improves the photocatalytic hydrogen production rate up to $220.74 \mu \mathrm{mol} \mathrm{h}-1 \mathrm{~cm}^{-2}$ for the wood/CoO system and $3271.49 \mu \mathrm{mol} \mathrm{h}^{-1} \mathrm{~cm}^{-2}$ for the wood/CuS-MoS 2 heterophotocatalyst.

\section{Results}

Constructing a photothermal-photocatalytic system on charred wood. A photothermal-photocatalytic system was skillfully designed and implemented by applying natural wood to generate water steam via photothermal transpiration under the light illumination simulated by a solar simulator at AM $1.5 \mathrm{G}$ illumination $\left(100 \mathrm{~mW} \mathrm{~cm}^{-2}\right)^{16-18}$. Also serving as the substrate for the photocatalytic reaction, a wood slice was cut from a tree perpendicular to its growth direction, and the surface of the wood slice was carbonized by a simple heating process for improving the steam generation with a high solar-to-steam-conversion efficiency of $46.90 \%$ (Fig. 1a and Supplementary Figs. 1-4) ${ }^{17}$. CoO nanoparticles (NPs), as a typical photocatalyst, were spin-coated on the carbonized wood slices to construct the wood/photocatalyst photothermal-photocatalytic system (here, the wood/CoO system), as shown in Fig. 1a. The monodispersed $\mathrm{CoO}$ NPs are $\sim 50 \pm 5 \mathrm{~nm}$ in diameter, and the $\mathrm{CoO}$ lattice fringes (with a d-spacing of $0.24 \mathrm{~nm}$ ) are assigned to the (111) lattice planes of $\mathrm{CoO}$, as shown in Supplementary Fig. $5^{19}$. The light absorption peak of the $\mathrm{CoO}$ NPs locates at $550 \mathrm{~nm}$ (Supplementary Fig. 6).

The CoO NPs are distributed $\sim 2 \mathrm{~mm}$ along the walls of the wood microchannels, as evidenced by the Raman spectra at different depths from the top surface (Fig. 1b), where only four
Raman spectra taken with an interval of $500 \mu \mathrm{m}$ from the surface show the $\mathrm{CoO}$ Raman characteristic peaks at 473.6 and $540.9 \mathrm{~cm}^{-120}$. When the wood/CoO system floats in the water, the immersion depth of the wood in the water is about $2 \mathrm{~mm}$ (Fig. 1c), indicating that the photocatalysts are not directly soaked in the liquid-phase water.

After CoO NPs coating on the wood, the wood/CoO system shows high light absorbance from 300 to $1000 \mathrm{~nm}$ compared to that of the pure wood, as shown in Fig. 1d, implying that the wood/CoO system can effectively utilize solar energy. Under light illumination, the surface temperature of the wood/CoO system is about $325 \mathrm{~K}$ (Fig. 1e), and the adhered photocatalysts become covered with steam produced by the photothermal transpiration in the wood interior. Simultaneously, the photo-induced electrons participate in the hydrogen evolution reaction at the photocatalytic active sites, and photo-induced holes participate in the $\mathrm{H}_{2} \mathrm{O}_{2}$ generation (Fig. 1a). It should be noted that the local temperature of the CoO NP is estimated to be $346 \mathrm{~K}$ based on the potential (Fig. 1f, g, and Supplementary Fig. 7) ${ }^{21}$, which is higher than the global temperature $(325 \mathrm{~K}$, in Fig. 1e) because of the nanoscale effect. It is speculated that a higher local temperature is beneficial to enhance the photocatalytic reaction efficiency.

We investigated the effect of CoO NPs mass loading on the photocatalytic hydrogen gas production rate in the wood/CoO system (Fig. 2a). An optimized mass loading of about $38 \mathrm{mg} \mathrm{cm}^{-2}$ $\mathrm{CoO}$ NPs has been identified based on the experimental results. The photocatalytic $\mathrm{H}_{2}$ evolution rate in the wood/CoO system with $38 \mathrm{mg} \mathrm{cm}^{-2} \mathrm{CoO}$ NPs loading is about $5776 \mu \mathrm{mol} \mathrm{h}^{-1} \mathrm{~g}^{-1}$ (i.e., $220.74 \mu \mathrm{mol} \mathrm{h}^{-1} \mathrm{~cm}^{-2}$ ), 17 times higher than that of the triphase CoO NPs $\left(337 \mu \mathrm{mol} \mathrm{h}^{-1} \mathrm{~g}^{-1}\right.$, agrees well with the values reported under similar conditions) ${ }^{19}$, as shown in Fig. 2 b. For clarification, the photocatalytic activity of wood alone was measured under the same condition (Supplementary Fig. 8), and no trace of hydrogen gas and oxygen gas were detected after $2 \mathrm{~h}$ of reaction, indicating that the wood does not have photocatalytic activity. Moreover, we also studied the effect of solar intensity on the photocatalytic response of the wood/CoO system. As shown in Fig. 2c, the rate of hydrogen evolution grows with the increase of solar intensity but not a linear relation. This is mainly because of the temperature rising on the wood/CoO surface caused by the increase in solar intensity (Supplementary Fig. 9). A higher temperature can exponentially improve the rate of hydrogen evolution, as evidenced in the following section.

In addition, the biphase wood/CoO system exhibits superior stability in photocatalytic activity. The long-period photocatalytic hydrogen production measurement with the wood/CoO system was conducted for 5 days (Fig. 2d). On day 1, the initial hydrogen production rate in $1 \mathrm{~h}$ is $221.56 \mu \mathrm{mol} \mathrm{h}-1 \mathrm{~cm}^{-2}$, and the average hydrogen production rate during $8 \mathrm{~h}$ reaction is $194.14 \mu \mathrm{mol} \mathrm{h}^{-1} \mathrm{~cm}^{-2}$. On day 5 , the average hydrogen production rate during $8 \mathrm{~h}$ reaction is $174.73 \mu \mathrm{mol} \mathrm{h}-1 \mathrm{~cm}^{-2}$. Thus, after 5 days $(40 \mathrm{~h})$ test, the photocatalytic hydrogen evolution performance maintains about $90 \%$, exhibiting that photocatalytic stability can be significantly improved through the wood/catalysts system compared to that in the previous work, which only holds $1 \mathrm{~h}$ of reaction ${ }^{22}$. We also studied the morphological stability of the wood/CoO system. After the photocatalytic reaction, the $\mathrm{CoO}$ NPs remain well attached to the wood matrix structure, further confirming the stability of the wood/CoO system (Fig. 2e, f, Supplementary Figs. 10 and 11). There is little difference in the reflection spectra and X-ray photoelectron spectroscopy (XPS) spectra of the wood/CoO system before and after the photocatalysis process (Supplementary Figs. 12 and 13). Besides, the inductively coupled plasma emission (ICP) and ultraviolet-visible (UV-Vis) spectra of the bulk water in the wood/CoO system after the photocatalytic reaction have been measured (Supplementary 


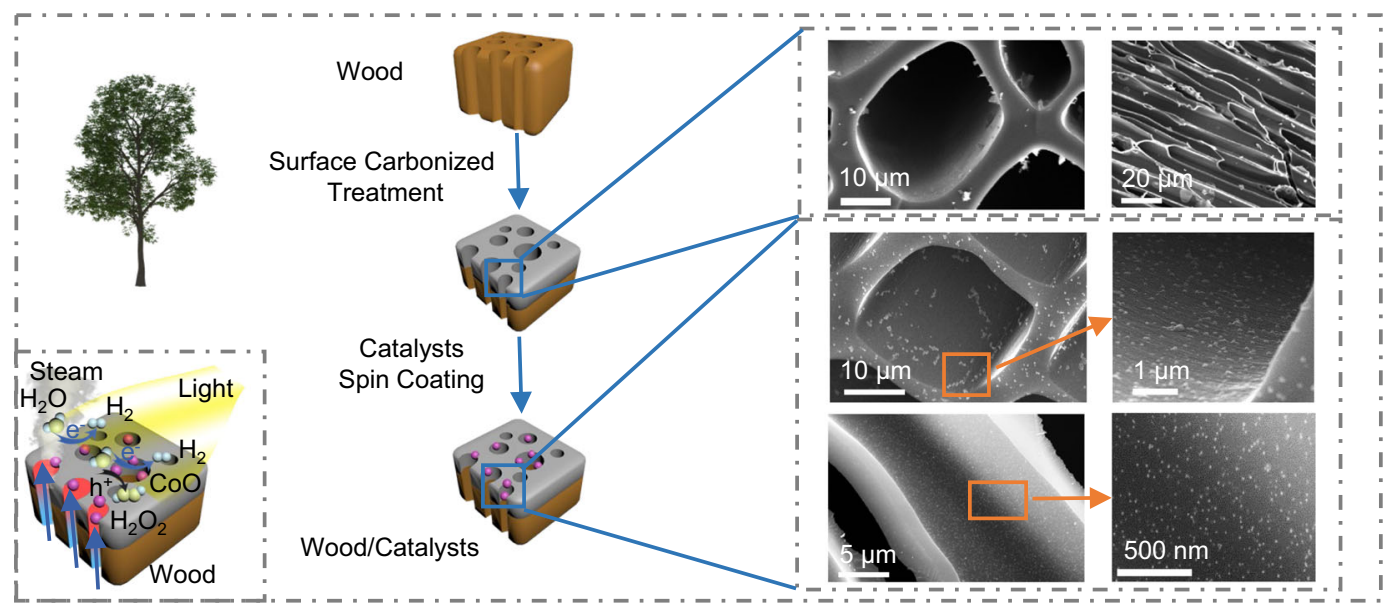

b
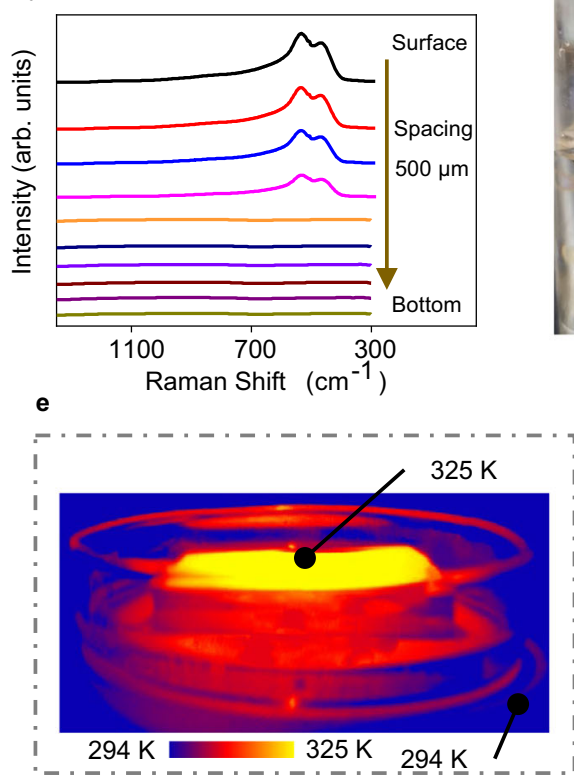

C
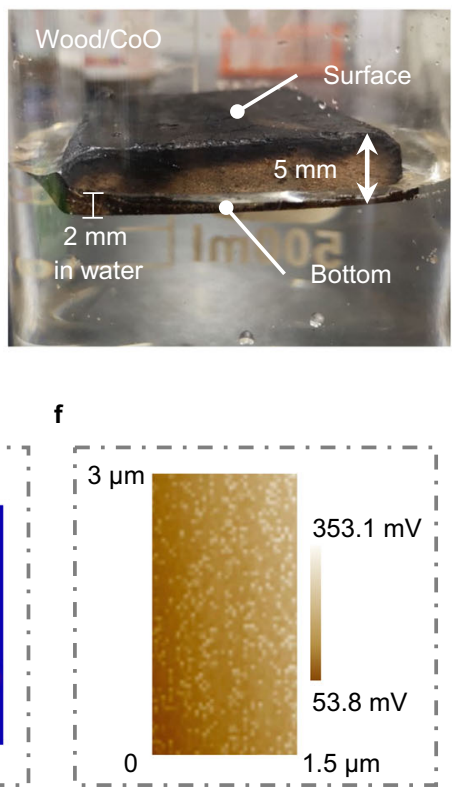

d
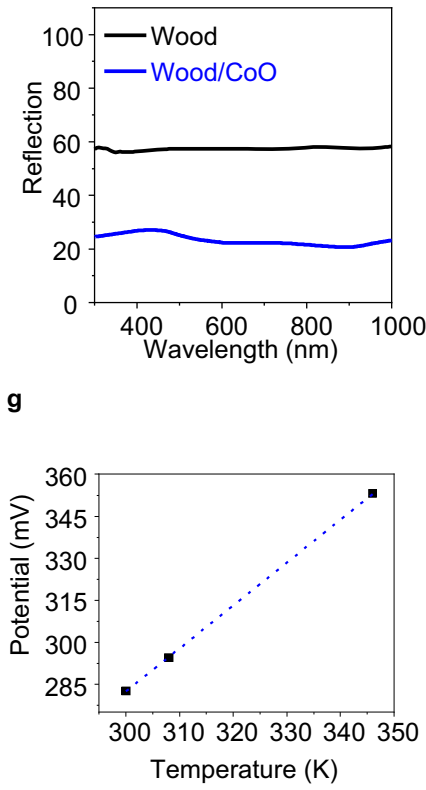

Fig. 1 The designed wood/photocatalyst biphase photothermal-photocatalytic system. a Schematic of the fabrication process of the wood/photocatalyst structure that generates the water steam and catalyzes its splitting for hydrogen evolution. b Raman spectra taken at different depths along the crosssection of wood/CoO microchannels with an interval of $500 \mu \mathrm{m}$. c The photo of the wood/CoO system floating on water. d Reflection spectra of the wood and wood/CoO systems. e Infrared radiation thermal image from the wood/CoO system under light illumination. $\mathbf{f}$ The potential of wood/CoO under $100 \mathrm{~mW} \mathrm{~cm}^{-2}$ light illumination. $\mathbf{g}$ The estimated local temperature of CoO NPs through the measured potential.

Fig. 14 and Supplementary Table 1). There are few amounts of element $\mathrm{Co}$ in the bulk water based on the ICP measurement results and the absorption spectrum, exhibiting the wood/CoO system's excellent stability. It can be concluded that the photothermal-photocatalytic system displays a significant advantage in substantially enhancing the $\mathrm{H}_{2}$ evolution rate from water splitting. It is noticed that the ratio of photocatalytic $\mathrm{H}_{2}$ and $\mathrm{O}_{2}$ production is not equal to 2:1 (Supplementary Figs. 15 and 16), mainly due to the generation of $\mathrm{H}_{2} \mathrm{O}_{2}$ by-product in the photocatalytic process (Supplementary Fig. 17).

Understanding the phase-interface effect on catalytic performance. From the phase-interface perspective, the photothermalphotocatalytic system exhibits biphase interfaces of photothermallygenerated steam/photocatalyst/hydrogen gas. To understand the phase-interface effect on the photocatalytic performance, we conducted experiments with a biphasic photocatalytic system containing injected water steam/solid photocatalysts (Fig. 3a and c). Water steam was injected and controlled by a steam flowmeter into a transparent reactor, where $\mathrm{CoO}$ NPs powder catalysts were placed on the surface of a filter paper, and no sacrificial agent was added to the photocatalytic system. Under light illumination, the steam in the reactor was photocatalytically converted to $\mathrm{H}_{2}$, which was detected by the gas chromatography (GC) (Fig. 3c). For comparison, the liquid/solid/gas triphase system of water/photocatalyst/hydrogen in common photocatalytic hydrogen evolution reaction has also been included. As shown in Fig. 3b, hydrogen bubbles are generated when the solid photocatalysts are interacting with liquid water under light illumination. The produced hydrogen gas is then collected by passive transport against the liquid water phase.

Hydrogen production in the biphase photocatalytic reaction system was evaluated with different flow rates of water steam (from 5 to $88 \mathrm{ml} \mathrm{h}^{-1}$ ) injected into the reactor chamber (Fig. 3c, d, Supplementary Figs. 18 and 19). The rate of hydrogen production from steam increases along with the increase of steam flow rate from 5 to $62 \mathrm{ml} \mathrm{h}^{-1}$. When the steam flow rate further grows, the hydrogen production rate is stabilized because the quantity of 
a

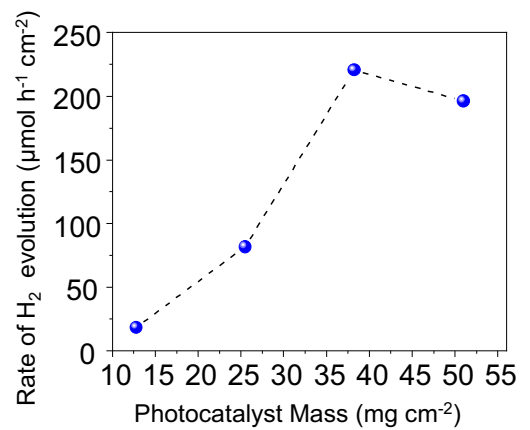

d

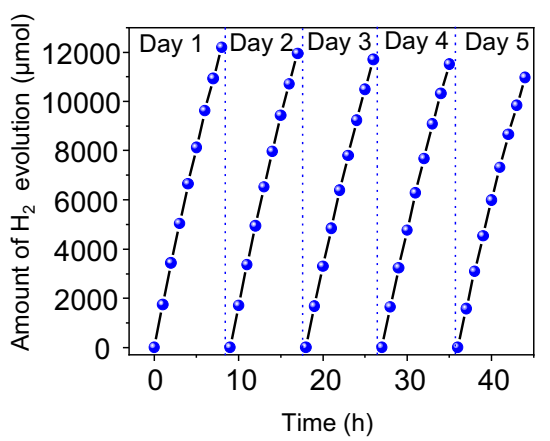

b

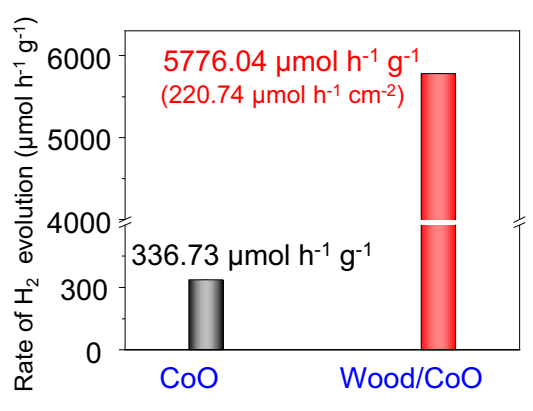

e

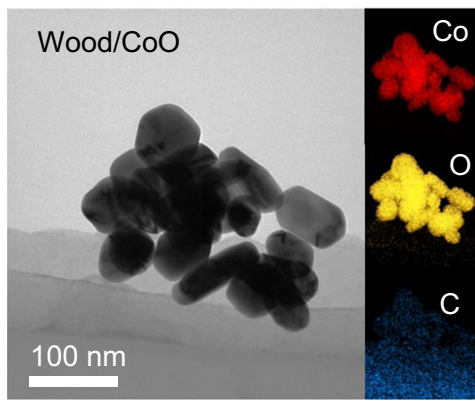

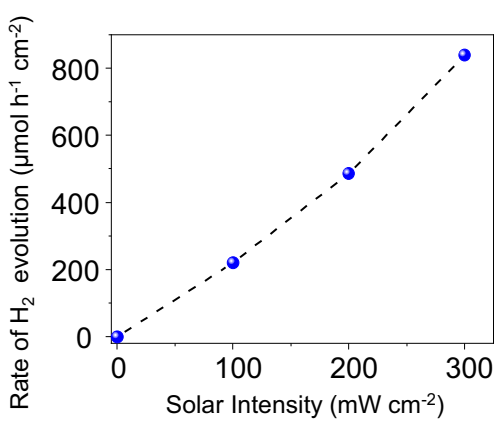

f

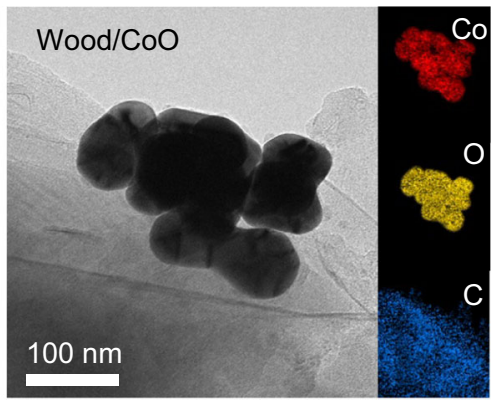

Fig. 2 Photocatalytic hydrogen evolution in the designed wood/photocatalyst biphase photothermal-photocatalytic system. a Mass loading-dependent photocatalytic hydrogen gas production rates for the wood/CoO system (area: $7.85 \mathrm{~cm}^{2}$ ). b Rate comparison of $\mathrm{H}_{2}$ evolution in the triphase $\mathrm{CoO} N P s$ system and wood/CoO biphase photothermal-photocatalytic system (area: $7.85 \mathrm{~cm}^{2}$, mass: $0.3 \mathrm{~g}$ ). c Rate of $\mathrm{H}_{2}$ evolution versus solar intensity from the wood/CoO system (area: $7.85 \mathrm{~cm}^{2}$, mass: $0.3 \mathrm{~g}$ ). d Time-dependent photocatalytic hydrogen gas production of the wood/CoO system for 5 days. The light source is a solar simulator at AM $1.5 \mathrm{G}$ illumination $\left(100 \mathrm{~mW} \mathrm{~cm}^{-2}\right)$. e TEM images and EDS element mapping of CoO NPs attached to the walls of the wood microchannels before the photocatalytic reaction. $\mathbf{f}$ TEM images and EDS element mapping of CoO NPs attached to the walls of the wood microchannels after the photocatalytic reaction.

water molecules reaches saturation during the photocatalytic reaction. At the optimal flow rate (i.e., $62 \mathrm{ml} \mathrm{h}^{-1}$ ), the maximum hydrogen evolution rate is $\sim 6200 \mu \mathrm{mol} \mathrm{h}^{-1} \mathrm{~g}^{-1}, 18$ times higher than that in the triphase reaction system $\left(337 \mu \mathrm{mol} \mathrm{h}-1 \mathrm{~g}^{-1}\right)$. The biphase photocatalytic system also shows excellent stability of the photocatalytic reaction, as shown in Fig. 3e. After three cyclic measurements, the amount of $\mathrm{H}_{2}$ evolution concurs with that in the first measurement. And the morphology and absorption spectra of $\mathrm{CoO}$ NPs after the photocatalytic reaction also keep unchanged, confirming the excellent stability of the photocatalyst (Supplementary Figs. 5, 20, and Fig. 3f).

The main factors governing the photocatalytic hydrogen evolution in the biphase reaction system are the temperature and the state of water in comparison to the triphase reaction system. Figure $4 \mathrm{a}$ shows the temperature-dependent of the photocatalytic hydrogen evolution rate with the $\mathrm{CoO}$ NPs photocatalyst in the triphase reaction system. As the reaction temperature increases from $298 \mathrm{~K}$ to close to $373 \mathrm{~K}$, the hydrogen evolution rate monotonically increases from 336.73 to $1968.9 \mu \mathrm{mol} \mathrm{h}^{-1} \mathrm{~g}^{-1}$ (note that $373 \mathrm{~K}$ is the steam-conversion temperature of liquid water). It should be noted, however, no trace hydrogen is detected after $2 \mathrm{~h}$ of reaction at near $373 \mathrm{~K}$ if light illumination is not applied, implying that the catalytic reaction cannot be thermally triggered (Supplementary Fig. 21). Furthermore, the relationship between the rate of $\mathrm{H}_{2}$ evolution reaction $V$ and the reaction temperature $T$ can be well-fitted with the Arrhenius equation:

$$
V=3748519.38 e^{-\left(\frac{23023}{8.314^{*} T}\right)}
$$

According to Eq. (1), the activation energy for the hydrogen production over $\mathrm{CoO}$ was deduced to be $23.023 \mathrm{~kJ} \mathrm{~mol}^{-1}$. The activation energy is a key indicator to reflect whether photocatalytic hydrogen evolution reaction occurs easily. The smaller the activation energy is, the easier the hydrogen production process will become. Therefore, a low activation energy here indicates that the hydrogen production process is easily conducted on the $\mathrm{CoO}$ NPs. Furthermore, the $\mathrm{H}_{2}$ evolution rate at $373 \mathrm{~K}$ is estimated to be $2236.76 \mu \mathrm{mol} \mathrm{h}^{-1} \mathrm{~g}^{-1}$. However, it is much lower than the $\mathrm{H}_{2}$ evolution rate $\left(6200.42 \mu \mathrm{mol} \mathrm{h}^{-1} \mathrm{~g}^{-1}\right.$, see Fig. 3d) in the biphase reaction system at the same temperature of $373 \mathrm{~K}$, indicating that the temperature effect on improving the $\mathrm{H}_{2}$ evolution rate is limited although a higher reaction temperature does promote the photocatalytic hydrogenevolution reaction. Thus, in addition to the reaction temperature, the state of water plays a crucial role in enhancing the hydrogen evolution of the biphasic reaction system.

The temperature effect can be systematically analyzed from two aspects: thermodynamics and kinetics. Three reaction steps, including the adsorption of water molecules, the adsorption of hydrogen atoms, and the hydrogen gas production in photocatalytic reaction, have been involved. First, the Gibbs energy in the triphase system has been calculated at 298 and $373 \mathrm{~K}$, where the pure $\mathrm{CoO}$ structure without any group is used to simulate the $\mathrm{CoO}$ status in the neutral environment because the $\mathrm{pH}$ value of the reactant water is approximately equal to 7 . As shown in Fig. 4 b, the change of reaction temperature from $298 \mathrm{~K}$ to $373 \mathrm{~K}$ influences the first and second steps. The Gibbs energy of the water molecule adsorption process at $298 \mathrm{~K}$ is about $0.426 \mathrm{eV}$, and it is about $0.145 \mathrm{eV}$ for the hydrogen adsorption process. 

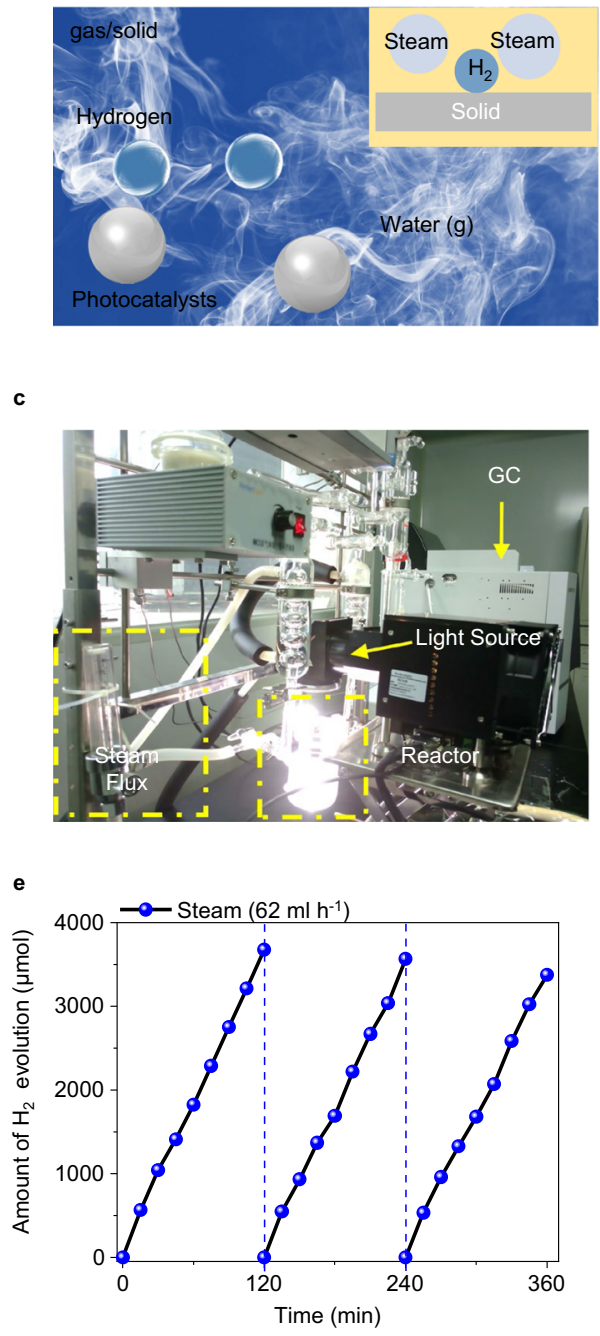

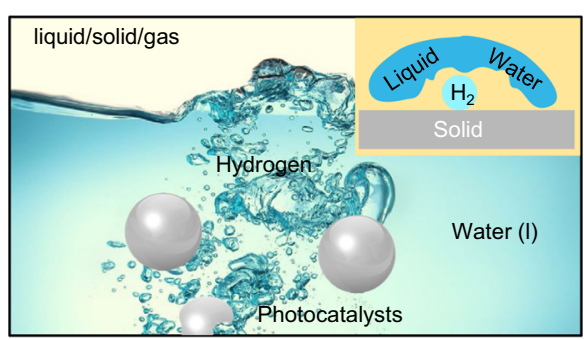

d

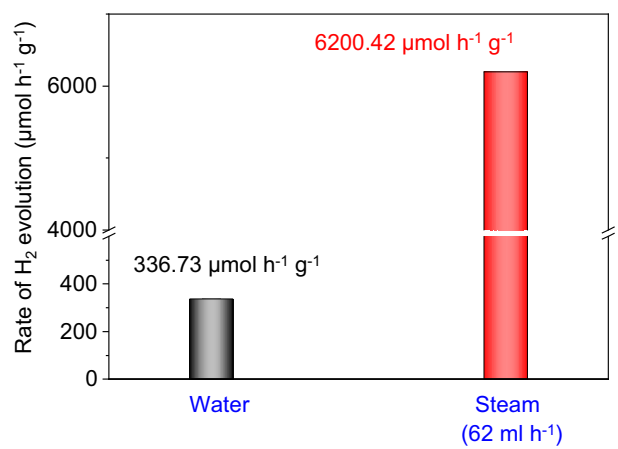

f

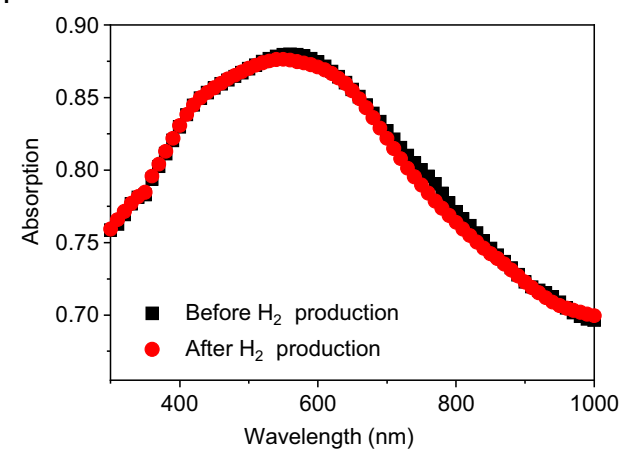

Fig. 3 Schematic and photocatalytic hydrogen evolution performance in the biphase and triphase reaction systems. a Schematic of the biphase system with water steam/solid photocatalysts/hydrogen gas. b Schematic of a typical triphase system consisting of liquid water/solid photocatalysts/hydrogen gas. c Photo of the biphase photocatalytic system. d Photocatalytic hydrogen gas production rate from the triphase and biphase reaction systems. e Timedependent photocatalytic hydrogen gas production from water steam with a flow rate of $62 \mathrm{ml} \mathrm{h}^{-1}$. The light source is a solar simulator at $\mathrm{AM} 1.5 \mathrm{G}$ illumination (100 $\mathrm{mW} \mathrm{cm}^{-2}$ ). f The absorption spectra of CoO NPs before and after hydrogen gas production.

Comparatively, they are reduced to 0.331 and $-0.054 \mathrm{eV}$, respectively, at $373 \mathrm{~K}$. As expected, the high reaction temperature in the triphase photocatalytic system would thermodynamically favor the water molecule adsorption process.

In addition to kinetically promote the transport of water molecules, high temperatures will reduce hydrogen transport resistance as well so that the photocatalytic reaction rate can be accelerated. This can be evidenced by the hydrogen gas diffusion coefficient $D_{\mathrm{L}}$ in a liquid-phase environment, calculated by the Stokes-Einstein equation:

$$
D_{\mathrm{L}}=7.4 \times 10^{-8} \frac{T\left(\psi_{\mathrm{H}_{2} \mathrm{O}} M_{\mathrm{H}_{2} \mathrm{O}}\right)^{0.5}}{\mu V_{\mathrm{H}_{2}}^{0.6}}
$$

where $T$ is the temperature, $\psi_{\mathrm{H}_{2} \mathrm{O}}(=2.26)$ is the "association" parameter of the solvent water, $M_{\mathrm{H}_{2} \mathrm{O}}$ and $\mu$ denote the molecular weight and viscosity of water, respectively, and $V_{\mathrm{H}_{2}}$ is the molar volume of hydrogen. When the temperature is increased from 298 to $373 \mathrm{~K}$, the hydrogen gas diffusion coefficient $D_{\mathrm{L}}$ is increased. Thus, hydrogen transport resistance is slightly decreased.
A more significant effect on promoting the photocatalytic hydrogen-evolution reaction comes from the state change of the water phase. When the water phase changes from liquid to steam at the same temperature $(373 \mathrm{~K})$, interestingly, the first and second step of the photocatalytic reaction (i.e., the water molecule adsorption process and the hydrogen adsorption process) has been significantly influenced. The Gibbs energy of the water molecule adsorption process substantially decreases from $0.331 \mathrm{eV}$ in the triphase system to $-0.212 \mathrm{eV}$ in the biphase system, and it also reduces $(-0.054$ vs. $-0.007 \mathrm{eV})$ for the hydrogen adsorption process (Fig. 4c), indicating that the water molecule adsorption process and hydrogen adsorption process in the biphase system become much more comfortable than that in the triphase system. Kinetically, the hydrogen gas diffusion coefficient $D_{\mathrm{G}}$ in the gaseous environment can be calculated by the Chapman-Enskog theory:

$$
D_{\mathrm{G}}=\frac{A * T^{3 / 2} \sqrt{\frac{1}{M_{\mathrm{H}_{2}}}+\frac{1}{M_{\mathrm{H}_{2} \mathrm{O}}}}}{P * \sigma^{2} * \Omega}
$$

where $A\left(=1.858 \times 10^{-3}\right)$ is an empirical coefficient ${ }^{23,24}, M$ is the 
a

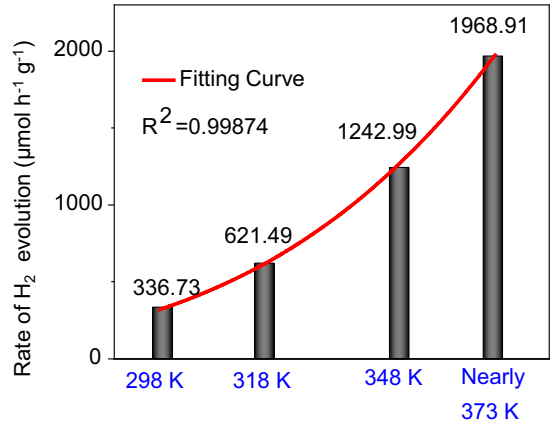

c

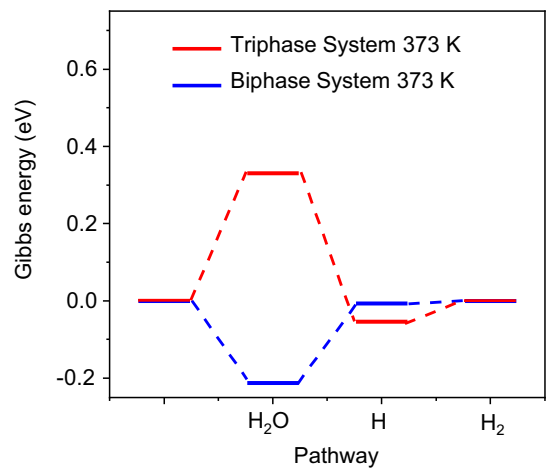

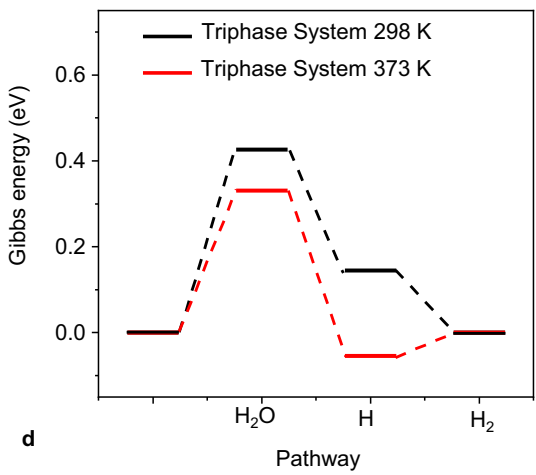

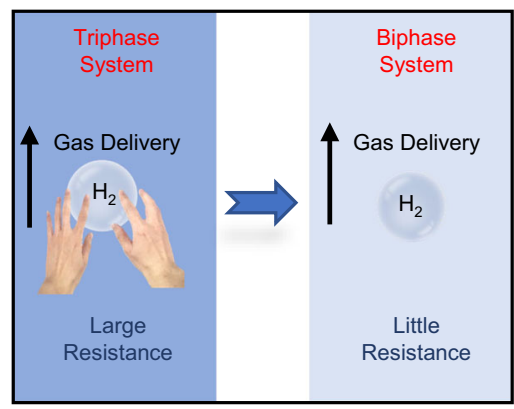

Fig. 4 The factors governing the biphase photocatalytic hydrogen evolution: temperature and liquid-to-gas-phase changes of water. a The photocatalytic hydrogen evolution rate with the $\mathrm{CoO}$ NPs versus the reaction temperature in the triphase reaction system. (Here, the background pressure was maintained at $5 \mathrm{kPa}$ ). $\mathbf{b}$ Gibbs energy of a photocatalytic reaction in the triphase system with different temperatures over the pure CoO surface. The photocatalyst is $\mathrm{CoO}$ NPs. c Gibbs energy of a photocatalytic reaction in the triphase system ( $373 \mathrm{~K})$ in comparison with the biphase system ( $373 \mathrm{~K}$ ) over the pure $\mathrm{CoO}$ surface. The photocatalyst is $\mathrm{CoO}$ NPs. $\mathbf{d}$ Schematic of the hydrogen transport resistances in the liquid- and gas-phase environments.

molar mass, $P$ is the pressure in the system, $\sigma$ is the average collision diameter, and $\Omega$ is a temperature-dependent collision integral. The produced hydrogen bubbles experience frictional resistance in adjacent interlayers from relative motion with the environmental particles ${ }^{25}$. Owing to the interfacial frictional resistance, the hydrogen-gas diffusion coefficients differ significantly in the liquid and steam water phases. In the liquid water phase, $D_{\mathrm{L}}$ is $(4.99-5.06) \times 10^{-5}$ at reaction temperatures near 373 $\mathrm{K}$ (i.e., $368-373 \mathrm{~K}$ ), based on the Stokes-Einstein equation (Eq. (2)), whereas, in the steam phase, $D_{\mathrm{G}}$ is $2.65 \times 10^{-3}$ at 373 $\mathrm{K}$, two orders of magnitude higher than that in the liquid water. Therefore, when the produced hydrogen gas passes through the liquid water before being liberated, it is greatly resisted by the environmental liquid water molecules. By contrast, the hydrogen bubbles in the biphase system pass through the gas water molecules with much less resistance. Figure $4 \mathrm{~d}$ schematizes the hydrogen transport resistances in the liquid- and gas-phase environments.

The universality of the photothermal-photocatalytic system. In addition to the exemplary wood/CoO system, the photothermalphotocatalytic system can also extend to other photocatalysts. To demonstrate the universal feature of the photothermalphotocatalytic biphase system, different photocatalysts, i.e., $\mathrm{MoS}_{2}$, $\mathrm{C}_{3} \mathrm{~N}_{4}$, and $\mathrm{TiO}_{2}$ were, respectively, spin-coated on the carbonized wood slices to construct wood/photocatalyst architectures (Fig. 5a-c and Supplementary Figs. 22-24). The $\mathrm{MoS}_{2}, \mathrm{C}_{3} \mathrm{~N}_{4}$, and $\mathrm{TiO}_{2}$ photocatalysts are all uniformly distributed and attached to the microchannel walls of the wood. The particulate photocatalytic hydrogen-evolution reactions were carried out in all the wood/ photocatalyst reaction systems (Fig. 5d and Supplementary Fig. 25).
All of the photocatalysts realize photothermal-photocatalytic hydrogen production, but no oxygen is detected at the same time because of the difficulty in downshifting the valence band positions (e.g., $\mathrm{MoS}_{2}, \mathrm{C}_{3} \mathrm{~N}_{4}$ ) and complex surface deformation reaction (e.g., $\left.\mathrm{TiO}_{2}\right)^{26-28}$. The $\mathrm{H}_{2}$ average production rates of the wood/ $\mathrm{MoS}_{2}$, wood $/ \mathrm{C}_{3} \mathrm{~N}_{4}$, and wood/TiO 2 photothermal-photocatalytic systems are $155.77,95.54$, and $59.87 \mu \mathrm{mol} \mathrm{h}^{-1} \mathrm{~cm}^{-2}$, respectively. For each photocatalyst, the apparent quantum yield (AQY) of the photothermal-photocatalytic biphase system dominates compared with the previously reported photocatalyst systems (Fig. 5e $)^{29-41}$, and the measured data are listed in Supplementary Table 2.

In addition to the monothetic particulate photocatalysts, a heterojunction photocatalyst, i.e., $\mathrm{CuS}-\mathrm{MoS}_{2}$, has also been introduced to the photothermal-photocatalytic systems to verify the universality (Supplementary Fig. 26). Similar to the monothetic particulate photocatalysts, the $\mathrm{CuS}-\mathrm{MoS}_{2}$ photocatalyst has adhered to the microchannel walls of the wood matrix, as shown in Fig. $5 \mathrm{f}$. The photocatalytic $\mathrm{H}_{2}$ average production rate of the biphase wood/CuS- $\mathrm{MoS}_{2}$ photothermal-photocatalytic system reaches up to $85,604 \mu \mathrm{mol} \mathrm{h}^{-1} \mathrm{~g}^{-1}$ (Supplementary Fig. 27), 16 times that of the triphase CuS-MoS ${ }_{2}$ photocatalyst $\left(5350 \mu \mathrm{mol} \mathrm{h}^{-1} \mathrm{~g}^{-1}\right)$ (Supplementary Fig. 28). It is noted that no photocatalytic oxygen gas was produced because of the energy band positions of the $\mathrm{CuS}-\mathrm{MoS}_{2}$ photocatalyst (Supplementary Fig. 29) ${ }^{42}$. It is speculated that the photo-induced holes react with some $\mathrm{S}$ ions from $\mathrm{CuS} /$ $\mathrm{MoS}_{2}$ catalyst as shown based on the XPS results (Supplementary Fig. 30$)^{43}$. Figure $5 \mathrm{~g}$ summarizes the $\mathrm{H}_{2}$ evolution rates of typical particulate photocatalysts reported to date. The $\mathrm{H}_{2}$ evolution rates were $70,000,64,426$, and $11,090 \mu \mathrm{mol} \mathrm{h}^{-1} \mathrm{~g}^{-1}$ in InP/ZnS ${ }^{44}$, PTB7Th/EH-IDTBR NPs ${ }^{45}$, and 2D/2D NiS/Vs-ZnIn ${ }_{2} \mathrm{~S}_{4} / \mathrm{WO}_{3}{ }^{46}$, respectively. They were 23,410 and $16,300 \mu \mathrm{mol} \mathrm{h}^{-1} \mathrm{~g}^{-1}$ based on the 


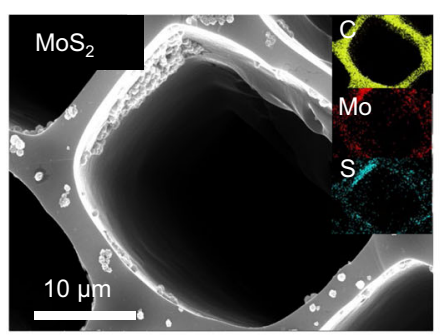

d

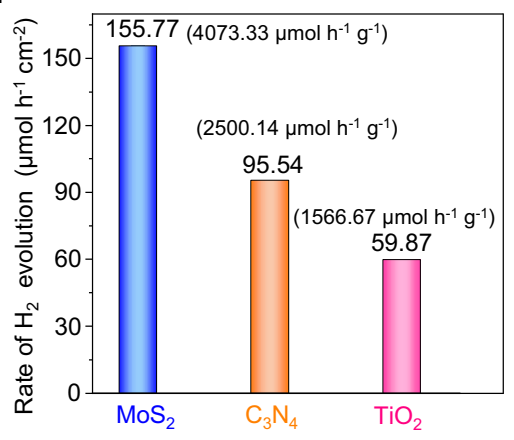

f

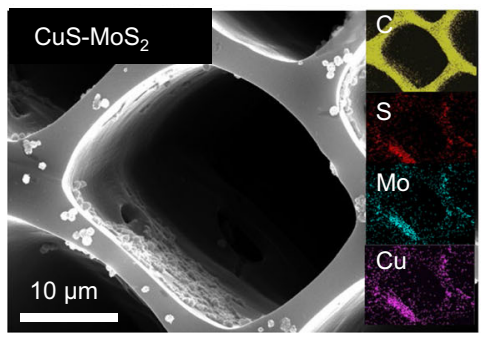

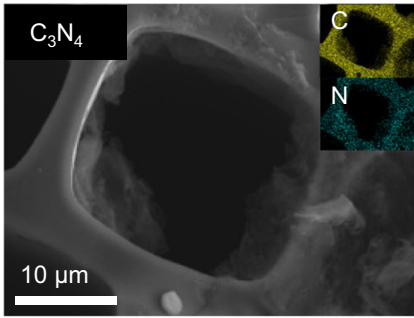

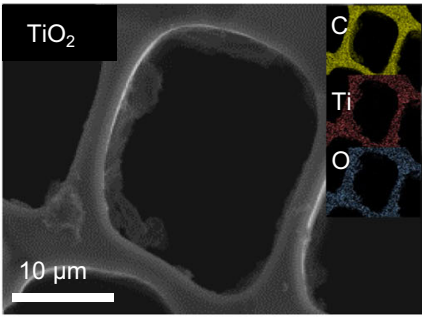

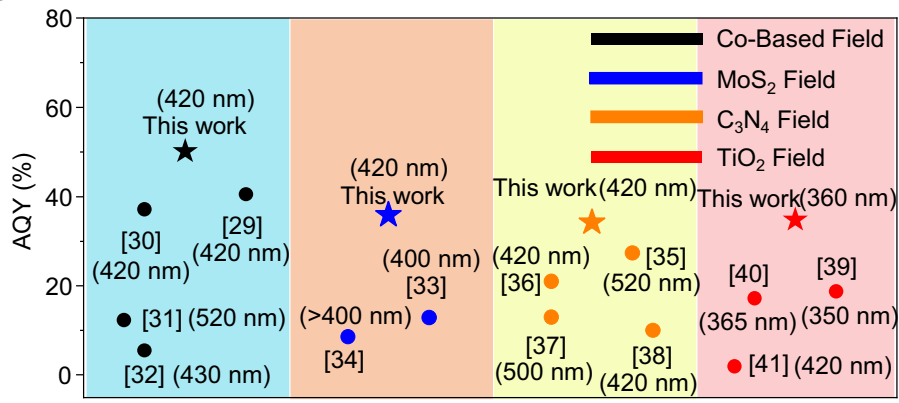

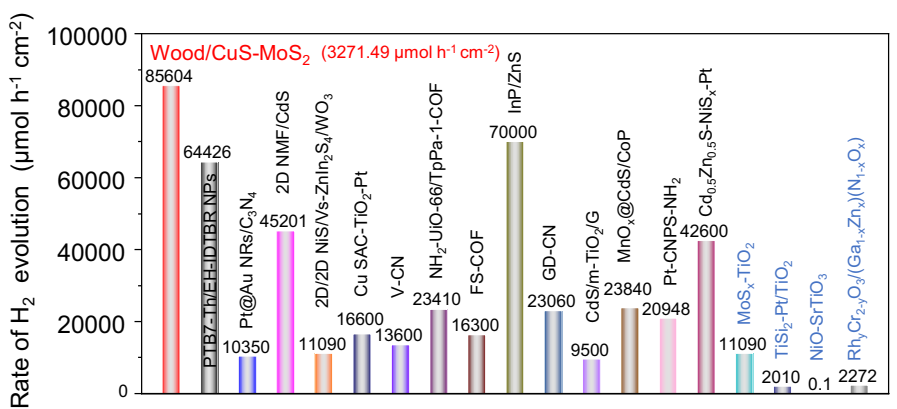

Fig. 5 The universal feature of the photothermal-photocatalytic biphase system for photocatalytic hydrogen evolution from water. a $S E M$ images and EDS mapping of the wood/MoS 2 . b SEM images and EDS mapping of the wood/C $\mathrm{N}_{4}$. c SEM images and EDS mapping of the wood/TiO 2 systems. d $\mathrm{H}_{2}$ evolution rates of the wood/ $\mathrm{MoS}_{2}$, wood/ $\mathrm{C}_{3} \mathrm{~N}_{4}$, and wood/TiO 2 systems. e Comparison of the AQY with literature in different particulate photocatalytic systems of $\mathrm{TiO}_{2}, \mathrm{C}_{3} \mathrm{~N}_{4}, \mathrm{MoS}_{2}$, and $\mathrm{Co}$-based photocatalysts, respectively. The numbers are the reference numbers and light wavelength. The maximum AQY data in literature and measurement results are presented for comparison. $\mathbf{f}$ SEM image and EDS mappings of the wood/CuS-MoS 2 photothermal-photocatalytic system. $\mathbf{g}$ Comparison of the $\mathrm{H}_{2}$ evolution rate of different particulate photocatalytic systems reported to date. The blue fonts on the right represent the photocatalytic reaction in the gas-phase water environment. The light source is a solar simulator at $\mathrm{AM} 1.5 \mathrm{G}$ illumination $\left(100 \mathrm{~mW} \mathrm{~cm}^{-2}\right)$.

COF materials ${ }^{47,48}$. The CdS-based photocatalysts including $2 \mathrm{D}$ $\mathrm{NMF} / \mathrm{CdS}^{49}, \mathrm{Cd}_{0.5} \mathrm{Zn}_{0.5} \mathrm{~S}-\mathrm{NiS}_{\mathrm{x}}-\mathrm{Pt}^{7}, \mathrm{MnO}_{\mathrm{x}} @ \mathrm{CdS} / \mathrm{CoP}^{50}$, and $\mathrm{CdS} /$ $\mathrm{m}-\mathrm{TiO}_{2} / \mathrm{G}^{51}$ achieved a $\mathrm{H}_{2}$ evolution rate of $45,201,42,600,23,840$, and $9500 \mu \mathrm{mol} \mathrm{h}^{-1} \mathrm{~g}^{-1}$, respectively. An $\mathrm{H}_{2}$ evolution rate of $16,600 \mu \mathrm{mol} \mathrm{h}^{-1} \mathrm{~g}^{-1}$ was reported on the $\mathrm{Cu} \mathrm{SAC}^{-\mathrm{TiO}_{2}-\mathrm{Pt}}$ photocatalyst ${ }^{52}$. The optimized $\mathrm{C}_{3} \mathrm{~N}_{4}$-based heterojunction photocatalysts, including GD-CN ${ }^{53}, \mathrm{Pt}-\mathrm{CNPS}-\mathrm{NH}_{2}{ }^{54}, \mathrm{~V}-\mathrm{CN}^{55}$, and Pt@Au NRs $/ \mathrm{C}_{3} \mathrm{~N}_{4}{ }^{56}$ achieved an $\mathrm{H}_{2}$ evolution rate of 23,060 , $20,948,13,600$, and $10,350 \mu \mathrm{mol} \mathrm{h}^{-1} \mathrm{~g}^{-1}$, respectively. In the reports involving vapor phase water, the photocatalytic hydrogen production rates were relatively low ${ }^{12,57,58}$, and the leader was $11,090 \mu \mathrm{mol} \mathrm{h}^{-1} \mathrm{~g}^{-1}$ based on the $\mathrm{MoS}_{\mathrm{x}}-\mathrm{TiO}_{2}$ hybrid ${ }^{11}$. The photothermal-photocatalytic system, i.e., the wood/CuS- $\mathrm{MoS}_{2}$ device, outperforms all of these photocatalysts with an $\mathrm{H}_{2}$ evolution rate of $85,604 \mu \mathrm{mol} \mathrm{h}^{-1} \mathrm{~g}^{-1}$ (i.e., $3271.49 \mu \mathrm{mol} \mathrm{h}^{-1} \mathrm{~cm}^{-2}$ ) without any external assistance, e.g., sacrificial agents, photovoltaic or photoelectrochemical assistance, demonstrating that the photothermal-photocatalytic biphase system can substantially enhance the photocatalytic hydrogen evolution from water.

Moreover, the photothermal-photocatalytic biphase system is promising for practical applications because it can easily be realized through the transpiration process of wood loaded with particulate photocatalysts. This natural process converts liquid water to steam under the same light illumination without additional energy input. As an example of a demonstration, the wood/CuS- $\mathrm{MoS}_{2}$ was put in a reaction cell filled with simulated seawater (Supplementary Fig. 31), and the hydrogen collector was connected to the gas outlet. When exposed to natural sunlight, the hydrogen collector exhibits a visible bulge after $2 \mathrm{~h}$ of reaction. Although the salts (e.g., $\mathrm{NaCl}$ ) in the seawater are possible to adhere to wood tunnels to clog the matrix structures, which lead to a decrease in steam production during evaporation ${ }^{59}$, the $\mathrm{H}_{2}$ production rate in this exemplary test is about $37,219 \mu \mathrm{mol} \mathrm{h}^{-1} \mathrm{~g}^{-1}$ (i.e., $1422.38 \mu \mathrm{mol} \mathrm{h}^{-1} \mathrm{~cm}^{-2}$ ) (measured by GC), confirming the strong photocatalytic ability in a seawater environment. And after $6 \mathrm{~h}$ of reaction, the $\mathrm{H}_{2}$ production rate remains consistent with that from the first test, exhibiting excellent photocatalytic stability.

\section{Discussion}

We have designed and demonstrated an integrated photothermalphotocatalytic system that helps achieve the dominant photocatalytic hydrogen evolution rate of $85,604 \mu \mathrm{mol} \mathrm{h}^{-1} \mathrm{~g}^{-1}$ (i.e., $3271.49 \mu \mathrm{mol} \mathrm{h}^{-1} \mathrm{~cm}^{-2}$ ) among the particulate photocatalysts. 
Such excellent performance was achieved by replacing the traditional triphase photocatalytic interfaces (liquid water/photocatalyst solid/hydrogen gas) with the biphase photocatalytic interfaces (photothermally-generated water steam/photocatalysts loaded on charred wood substrates/hydrogen gas). The wood carrier functions simultaneously as the photocatalyst substrate as well as the steam generator under solar light, which is significantly advantageous for practical applications. This photothermalphotocatalytic system reduced the barrier of the water molecule adsorption process and minimized the delivery resistance of the produced hydrogen gas, enabling efficient and environmentally safe fuel for next-generation applications on an industrial scale.

\section{Methods}

Synthesis of $\mathrm{CoO}_{1} \mathrm{MoS}_{2}, \mathrm{C}_{3} \mathrm{~N}_{\mathbf{4}}, \mathrm{TiO}_{2}$, and CuS-MoS photocatalysts. CoO NPs were fabricated by a heating process with the hydrothermal method and a tube furnace. In all, $2 \mathrm{~g}$ of $\mathrm{Co}\left(\mathrm{CH}_{3} \mathrm{COO}\right)_{2} \cdot 4 \mathrm{H}_{2} \mathrm{O}$ powder was added to a mixed solvent with $8 \mathrm{ml} \mathrm{n}$-octanol and $32 \mathrm{ml}$ ethanol by stirring for $3 \mathrm{~h}$. After that, the mixture was transferred to a $50 \mathrm{ml}$ Teflon-lined stainless steel autoclave, and then heated at $200{ }^{\circ} \mathrm{C}$ for $6 \mathrm{~h}$. When the autoclave was cooled down to room temperature, the powders were placed in a quartz tube furnace. The tube was filled to ambient pressure with Ar gas flowing at 240 s.c.c.m. The Ar flow rate and $1 \mathrm{~atm}$. pressure were maintained throughout the preparation process. The tube was continuously heated from $25^{\circ} \mathrm{C}$ to $600{ }^{\circ} \mathrm{C}$ in $3 \mathrm{~h}$. After maintaining the tube furnace at $600{ }^{\circ} \mathrm{C}$ for $5 \mathrm{~h}$, the tube was cooled to room temperature over $5 \mathrm{~h}$. The obtained powders were then dispersed in pure water, and the $\mathrm{CoO}$ NPs were obtained by centrifugation at $1677 \times g$ for $10 \mathrm{~min}$ (Anke TGL-15B Centrifuger). After that, the prepared photocatalysts $(0.3 \mathrm{~g})$ were added to the surface of the filter paper by spin coating at $500 \mathrm{rpm}$ for $20 \mathrm{~s}$. Then the filter paper with photocatalyst was taken into the oven at $40^{\circ} \mathrm{C}$ for $1 \mathrm{~h}$.

For the $\mathrm{MoS}_{2}$ synthesis, solutions of $2.0 \mathrm{mmol} \mathrm{Na}_{2} \mathrm{MoO}_{4}$ and $4.0 \mathrm{mmol} \mathrm{L}$ cysteine were sterilized in a $50 \mathrm{ml}$ Teflon-lined stainless steel autoclave. The autoclave was heated at $200^{\circ} \mathrm{C}$ for $12 \mathrm{~h}$ and naturally cooled to room temperature, obtaining the $\mathrm{MoS}_{2}$ solution. For the $\mathrm{C}_{3} \mathrm{~N}_{4}$ synthesis, $0.5 \mathrm{~g} \mathrm{C}_{3} \mathrm{~N}_{4}$ powder was exfoliated in deionized water $(400 \mathrm{ml})$ for $8 \mathrm{~h}$ with a probe ultrasonication cleaner ( $200 \mathrm{~W}, \mathrm{UP} 400 \mathrm{~S})$. The dispersion was then centrifuged at $2029 \times \mathrm{g}$ for $20 \mathrm{~min}$, yielding the $\mathrm{C}_{3} \mathrm{~N}_{4}$ photocatalyst. $\mathrm{TiO}_{2}$ was synthesized by the nonhydrolytic sol-gel approach described as follows. A solution of $\mathrm{TiCl}_{4}(1 \mathrm{ml})$, ethanol $(5 \mathrm{ml})$, and benzyl alcohol $(35 \mathrm{ml})$ was incubated for $6 \mathrm{~h}$ at $80^{\circ} \mathrm{C}$, then washed three times with diethyl ether. After centrifuging the crude product at $2415 \times \mathrm{g}$ for $10 \mathrm{~min}$, a white $\mathrm{TiO}_{2}$ precipitate was obtained. The final $\mathrm{TiO}_{2}$ solution was prepared by dispersing the precipitate in ethanol.

For the CuS-MoS 2 synthesis, the process was divided into two steps. A Cu-Mobased metal-organic framework (i.e., NENU-5) was first prepared through a wet chemical method. $0.6 \mathrm{~g}$ copper (II) acetate monohydrate and $1.2 \mathrm{~g}$

phosphomolybdic acid hydrate were mixed and sonicated in $40 \mathrm{~mL}$ DI water for 30 min. $0.62 \mathrm{~g}$ trimeric acid, which was dissolved in $40 \mathrm{ml}$ ethanol, was poured into the above solution quickly, and the nanocrystal NENU-5 was obtained. Second, $2 \mathrm{~g}$ sulfur powder and $0.1 \mathrm{~g}$ NENU- 5 were placed in a dual-zone tube furnace upstream region $\left(250^{\circ} \mathrm{C}\right)$ and down-stream region $\left(550^{\circ} \mathrm{C}\right)$, respectively. The $\mathrm{CuS}-\mathrm{MoS}_{2}$ heterojunction was prepared after $1 \mathrm{~h}$ reaction under $\mathrm{Ar}$ gas environment.

Synthesis of wood/photocatalyst systems. Pinewood blocks were cut into pieces using a sweep saw (area: $7.85 \mathrm{~cm}^{2}$, thickness: $5 \mathrm{~mm}$ ). The whole carbonized wood was directly obtained through heating the woodblock in a muffle furnace at a temperature of $300^{\circ} \mathrm{C}$ for $2 \mathrm{~h}$. To improve the steam generation, the surface of the wood slice was treated by a simple heating process to obtain the surface carbonized wood. In detail, the wood samples were pretreated in an alcohol flame for $2 \mathrm{~min}$, then immediately immersed in cold water at room temperature for rapid quenching. Next, the NP solutions ( $0.3 \mathrm{~g}$ of $\mathrm{CoO}, \mathrm{MoS}_{2}, \mathrm{C}_{3} \mathrm{~N}_{4}, \mathrm{TiO}_{2}$, or $\mathrm{CuS}-\mathrm{MoS}_{2}$ ) were spin-coated onto the wood surface at $500 \mathrm{rpm}$ for $20 \mathrm{~s}$. Finally, the samples were dried in an oven at $45^{\circ} \mathrm{C}$ for $2 \mathrm{~h}$, yielding the wood/catalyst systems. The different $\mathrm{CoO}$ loadings $(0.1,0.2,0.3$, and $0.4 \mathrm{~g})$ were realized by changing the photocatalyst solution concentration.

Characterization of the photocatalysts. The morphologies of the samples were characterized by a scanning electron microscope (SEM) (FEI NOVASEM) and a transmission electron microscope (TEM) (FEI Talos F200X). The infrared radiation thermal image from the wood/CoO system under light illumination was recorded with a UTi80 thermal imager. XPS spectra of wood/CoO and element S for $\mathrm{CuS} / \mathrm{MoS}_{2}$ were collected through Kratos Axis supra XPS spectrometer.The local temperature of $\mathrm{CoO}$ NPs was estimated through the atomic force microscopy (AFM) (Bruker Dimension Icon). At the 300 and $308 \mathrm{~K}$, the potentials of wood/ $\mathrm{CoO}$ were measured. After that, the potential of wood/CoO was recorded under
$100 \mathrm{~mW} \mathrm{~cm}{ }^{-2}$ light illumination. Due to the correlation between potential and the temperature ${ }^{21}$, the local temperature of $\mathrm{CoO}$ under light illumination could be estimated. The bulk water of wood/CoO was measured through Perkin Elmer Lambda 35 ultraviolet-visible spectrophotometer and Thermo Fisher ICAP7600DUO inductively coupled plasma emission spectrometer.

Solar-driven-steam generation measurements. Steam generation from the wood was measured in a quartz beaker containing deionized (DI) water. The solar light was simulated by a solar simulator at AM $1.5 \mathrm{G}$ illumination $\left(100 \mathrm{~mW} \mathrm{~cm}^{-2}\right)$, and the mass changes in the water were measured by a high-accuracy balance (Mettler-Toledo, ME204E). The quartz beaker containing the wood in DI water was placed on the balance, and the weight loss of the water was recorded by reading the balance every 3 min under light illumination.

The solar-to-steam-conversion efficiency $\eta$ was calculated as:

$$
\eta=\frac{\Delta m * \Delta \operatorname{vap} * \mathrm{H}}{M * P * S * T}
$$

where $\Delta m$ is the mass loss of water during irradiation, $\Delta \mathrm{vap}^{*} \mathrm{H}$ is the phase change enthalpy of water from liquid to vapor which is $\sim 40.637 \mathrm{~kJ} \mathrm{~mol}^{-1}, M$ is the molar mass of water, $P$ is the solar power density $\left(100 \mathrm{~mW} \mathrm{~cm}^{-2}\right), S$ is the area (about $\left.7.85 \mathrm{~cm}^{2}\right)$, and $T$ is the irradiation time $(3600 \mathrm{~s})$.

Hydrogen generation tests. For the hydrogen evolution measurement in the liquid water/photocatalysts/hydrogen-gas triphase system, $50 \mathrm{ml}$ of deionized water was added to the transparent reactor chamber, and then the filter paper with photocatalyst was immersed in the water. The reaction cell was placed $7.0 \mathrm{~cm}$ from the light source. The light source was a solar simulator at AM $1.5 \mathrm{G}$ illumination $\left(100 \mathrm{~mW} \mathrm{~cm}^{-2}\right.$ ) (CEL-NP2000) (Supplementary Fig. 32), which was equipped with a fan that efficiently dissipated the excess heat. The reaction temperature in the quartz cell was tuned through a heating jacket and was measured by a thermometer. During the photocatalytic reaction, the gases were transferred into the sample loop by a peristaltic pump and were further quantified by gas chromatography (Shimadzu GC-2014c; Ar carrier gas and molecular sieve-5A column), equipped with a thermal conductivity detector. The hydrogen-gas yield of the reactor was measured every $15 \mathrm{~min}$.

The hydrogen evolution in the injected water steam/photocatalysts biphase system was carried out similarly to the triphase reaction measurement. The filter paper with photocatalysts was taken to the middle of the quartz cell. The steam was injected into the quartz cell, and the steam flowmeter was used to monitor the steam flux. The remaining testing process in the biphase system was similar to that of the triphase system hydrogen evolution.

The AQY is calculated based on the formula below 60 :

$$
\mathrm{AQY}=\frac{2 * n * N_{\mathrm{A}}}{(E * A * T * \lambda) /(h * C)} \times 100 \%
$$

where $n$ is the $\mathrm{H}_{2}$ yield, $N_{\mathrm{A}}$ is the Avogadro number, $E$ is light intensity, $A$ is the irradiation area, $T$ is the time, $\lambda$ is the wavelength, $h$ is the Planks constant, and $C$ is the speed of light.

The $\mathrm{H}_{2} \mathrm{O}_{2}$ concentration was determined through UV-Vis absorption spectra ${ }^{61}$ $0.01 \mathrm{~mol} \mathrm{~L}^{-1}$ copper (II) sulfate solution was prepared in advance, and $1 \mathrm{~g}$ neocuproine was dissolved in $100 \mathrm{ml}$ ethanol to obtain 2,9-dimethyl-1,10phenanthroline (DMP) solution. $5 \mu \mathrm{mol} \mathrm{ml}^{-1} \mathrm{H}_{2} \mathrm{O}_{2}$ was used as a standard sample to react with copper (II) sulfate solution and DMP solution. The obtained absorption spectrum was the baseline. Then, the solutions after photocatalytic reaction were mixed with copper (II) sulfate solution and DMP solution to measure related absorption spectra, which could be utilized to calculate the $\mathrm{H}_{2} \mathrm{O}_{2}$ concentration through comparing with the baseline.

The hydrogen evolution measurement in the wood/photocatalyst photothermal-photocatalytic system was carried out similarly to the triphase reaction measurement. The quartz cell contained $50 \mathrm{ml}$ of deionized water. The wood/photocatalyst systems were floating on the water. The remaining testing process was similar to that of the triphase system hydrogen evolution measurement. In simulated seawater splitting to hydrogen measurement, the simulated seawater contains $3.1 \mathrm{wt} \% \mathrm{NaCl}, 0.2 \mathrm{wt} \% \mathrm{MgCl}_{2}$, and $0.1 \mathrm{wt} \% \mathrm{KCl}$; and the wood/photocatalyst systems ( $0.3 \mathrm{~g} \mathrm{CuS}-\mathrm{MoS}_{2}$ were loaded) were floating on the simulated seawater. After the photocatalytic reaction, the hydrogen collector was taken to be measured through gas chromatography. The hydrogen collector was replaced by a new one every $2 \mathrm{~h}$ to carry out the photocatalytic stability measurement.

Theoretical calculation. All periodic calculations were performed in the Vienna $\mathrm{Ab}$ Initio Simulation Package (VASP), which was on the basis of the generalized gradient approximation (GGA) and the exchange-correlation energy of interacting electrons determined by the revised-Perdew-Burke-Ernzerhof (RPBE) functional. The ion-electron interaction was described with the projector augmented wave (PAW) method ${ }^{62}$. A basis set of plane waves was up to an energy cutoff of $520 \mathrm{eV}$ The $\mathrm{CoO}(111)$ surface was modeled with a $2 \times 2$ supercell containing 13 atomic layers, where 5 layers were fixed in the bulk positions. All slab structure included a vacuum of $15 \AA$. The dipole moment correction was considered and added in calculation optimization process. And the antiferromagnetic moment was set up 
along the (111) direction. A U value of $4.1 \mathrm{eV}$ was applied to the Co d-states. The Monkhorst-pack method with the centered k-point grid $(4 \times 4 \times 1)$ was used for surface calculations, respectively. The convergence threshold for the residual force was set to $0.02 \mathrm{eV}^{-1}$, and energies have converged within $10^{-5} \mathrm{eV}$. The model structure schemes and band structures of $\mathrm{CoO}$ have been shown in the Supplementary Figs. 33 and 34.

The hydrogen and water adsorption energy on various surfaces is defined as ${ }^{63,64}$

$$
\begin{gathered}
\Delta E_{\text {ads }}=E_{\text {base- } \mathrm{H}}-E_{\text {base }}-\frac{1}{2} E_{\mathrm{H}_{2}} \\
\Delta E_{\text {ads }}=E_{\text {base- } \mathrm{H}_{2} \mathrm{O}}-E_{\text {base }}-E_{\mathrm{H}_{2} \mathrm{O}}
\end{gathered}
$$

where $E_{\text {base- } \mathrm{H}}$ and $E_{\text {base- } \mathrm{H}_{2} \mathrm{O}}$ are the total energy of the slab model with $\mathrm{H}$ and $\mathrm{H}_{2} \mathrm{O}$ adsorption, $E_{\text {base }}$ is the energy of a clean slab surface, and $E_{\mathrm{H} 2}$ and $E_{\mathrm{H} 2 \mathrm{O}}$ are that for hydrogen and water molecules.

The Gibbs energy can be calculated by taking zero-point energy and entropy corrections into account ${ }^{65}$ such that $\Delta G=\Delta E+\Delta E_{\mathrm{ZPE}}-\mathrm{T} \Delta S+\Delta G_{\mathrm{pH}}$. Where $\Delta E_{\mathrm{ZPE}}$ and $\mathrm{T} \Delta S$ are the difference in zero-point energy and entropy between the adsorbed species and free species in the gas phase, respectively ${ }^{66,67}$. At different $\mathrm{pH}$ values, $\Delta G_{\mathrm{pH}}=0.059 \times \mathrm{pH}$. The solvent effect is considered through the implicit solvation model based on the VASPsol ${ }^{68,69}$. The dielectric constants of liquid water and gas water are indexed to be 81 and 1, respectively. The differences of Gibbs free energies in the bi- and tri-phasic systems are the temperature (373 and $298 \mathrm{~K}$, respectively) and the entropy change $\Delta S$. The dielectric constant and entropy change $\Delta S$ correction in the vapor water and liquid water was obtained from the Handbook of Chemistry and Physics ${ }^{70}$. The entropy $S$ is $0.367 \mathrm{~kJ} \mathrm{~kg}^{-1} \mathrm{~K}^{-1}$ at $298 \mathrm{~K}$ under the standard pressure, while at $373 \mathrm{~K}$ the entropy $S$ is $1.303 \mathrm{~kJ} \mathrm{~kg}^{-1} \mathrm{~K}^{-1}$ when the water is liquid (the value is used for Gibbs free energies calculation in tri-phasic systems at $373 \mathrm{~K}$ ) and $7.361 \mathrm{~kJ} \mathrm{~kg}^{-1} \mathrm{~K}^{-1}$ when the water is in the gas phase (the value is used for Gibbs free energies calculation in biphasic systems at $373 \mathrm{~K})$.

\section{Data availability}

The authors declare that the data supporting the findings of this study are available within this paper and its Supplementary information file, or from the corresponding authors.

Received: 3 June 2020; Accepted: 7 January 2021;

Published online: 26 February 2021

\section{References}

1. Voiry, D., Shin, H. S., Loh, K. P. \& Chhowalla, M. Low-dimensional catalysts for hydrogen evolution and $\mathrm{CO}_{2}$ reduction. Nat. Rev. Chem. 2, 0105 (2018).

2. Chen, S., Takata, T. \& Domen, K. Particulate photocatalysts for overall water splitting. Nat. Rev. Mater. 2, 17050 (2017).

3. Zhang, J. Q. et al. Single platinum atoms immobilized on an MXene as an efficient catalyst for the hydrogen evolution reaction. Nat. Catal. 1, 985-992 (2018).

4. Pinaud, B. A. et al. Technical and economic feasibility of centralized facilities for solar hydrogen production via photocatalysis and photoelectrochemistry. Energy Environ. Sci. 6, 1983-2002 (2013).

5. Guo, L. et al. $\mathrm{MoS}_{2} / \mathrm{TiO}_{2}$ heterostructures as nonmetal plasmonic photocatalysts for highly efficient hydrogen evolution. Energy Environ. Sci. 11, 106-114 (2018).

6. Wang, Q. et al. Scalable water splitting on particulate photocatalyst sheets with a solar-to-hydrogen energy conversion efficiency exceeding 1\%. Nat. Mater. 15, 611-615 (2016).

7. Liu, M. C. et al. Photocatalytic hydrogen production using twinned nanocrystals and an unanchored $\mathrm{NiS}_{\mathrm{x}}$ co-catalyst. Nat. Energy 1, 16151 (2016).

8. Dionigi, F. et al. Gas phase photocatalytic water splitting with $\mathrm{Rh}_{2-\mathrm{y}} \mathrm{Cr}_{\mathrm{y}} \mathrm{O}_{3}$ / GaN:ZnO in $\mu$-reactors. Energy Environ. Sci. 4, 2937-2942 (2011).

9. Kistler, T. A., Um, M. Y. \& Agbo, P. Stable photoelectrochemical hydrogen evolution for $1000 \mathrm{~h}$ at $14 \%$ efficiency in a monolithic vapor-fed device. $J$. Electrochem. Soc. 167, 066502 (2020)

10. Zafeiropoulos, G., Johnson, H., Kinge, S., van de Sanden, M. C. M. \& Tsampas, M. N. Solar hydrogen generation from ambient humidity using functionalized porous photoanodes. ACS Appl. Mater. Inter. 11, 41267-41280 (2019).

11. Daeneke, T. et al. Surface water dependent properties of sulfur-rich molybdenum sulfides: electrolyteless gas phase water splitting. ACS Nano 11, 6782-6794 (2017).

12. Isogai, $\mathrm{S}$. et al. Composite of $\mathrm{Rh}_{\mathrm{y}} \mathrm{Cr}_{2-\mathrm{y}} \mathrm{O}_{3} /\left(\mathrm{Ga}_{1-\mathrm{x}} \mathrm{Zn}_{\mathrm{x}}\right)\left(\mathrm{N}_{1-\mathrm{x}} \mathrm{O}_{\mathrm{x}}\right)$ photocatalysts with hydrophobic polytetrafluoroethylene (PTFE) membranes for the fabrication of novel reaction sites for water vapor splitting under visible light. Catal. Lett. 143, 150-153 (2013).
13. Yin, Q. Q. et al. Plasmonic molybdenum oxide nanosheets supported silver nanocubes for enhanced near-infrared antibacterial activity: synergism of photothermal effect, silver release and photocatalytic reactions. Appl. Catal. BEnviron. 224, 671-680 (2018).

14. Yan, B., Du, C., Lin, Z. Y. \& Yang, G. W. Photothermal conversion assisted photocatalytic hydrogen evolution from amorphous carbon nitrogen nanosheets with nitrogen vacancies. Phys. Chem. Chem. Phys. 22, 4453-4463 (2020).

15. Lu, L. L., Xu, X. X., An, K. L., Wang, Y. \& Shi, F. N. Coordination polymer derived NiS@g- $\mathrm{C}_{3} \mathrm{~N}_{4}$ composite photocatalyst for sulfur vacancy and photothermal effect synergistic enhanced $\mathrm{H}_{2}$ production. ACS Sustain. Chem. Eng. 6, 11869-11876 (2018)

16. Jia, C. et al. Rich mesostructures derived from natural woods for solar steam generation. Joule 1, 588-599 (2017).

17. Xue, G. et al. Robust and low-cost flame-treated wood for high-performance solar steam generation. ACS Appl. Mater. Inter. 9, 15052-15057 (2017).

18. He, S. M. et al. Nature-inspired salt resistant bimodal porous solar evaporator for efficient and stable water desalination. Energy Environ. Sci. 12, 1558-1567 (2019).

19. Zhan, X. Y. et al. Efficient $\mathrm{CoO}$ nanowire array photocatalysts for $\mathrm{H}_{2}$ generation. Appl. Phys. Lett. 105, 153903 (2014).

20. Shi, W. L. et al. Carbon dots anchored on octahedral CoO as a stable visiblelight-responsive composite photocatalyst for overall water splitting. J. Mater. Chem. A 37, 19800-19807 (2017).

21. Majumdar, A. Scanning thermal microscopy. Annu. Rev. Mater. Sci. 29 505-585 (1999).

22. Liao, L. et al. Efficient solar water-splitting using a nanocrystalline $\mathrm{CoO}$ photocatalyst. Nat. Nanotechnol. 9, 69-73 (2014).

23. Gallis, M. A., Torczynski, J. R. \& Rader, D. J. Molecular gas dynamics observations of Chapman-Enskog behavior and departures there from in nonequilibrium gases. Phys. Rev. E Stat. Nonlin. Soft Matter Phys. 69, 042201 (2004).

24. Fernandez de la Mora, J. \& Fernandez-Feria, R. Two-fluid Chapman-Enskog theory for binary gas mixtures. Phys. Fluids 30, 2063 (1987).

25. Xie, D. G. et al. In situ study of the initiation of hydrogen bubbles at the aluminium metal/oxide interface. Nat. Mater. 14, 899-903 (2015).

26. Pan, Z., Zhang, G. \& Wang, X. Polymeric carbon nitride/reduced graphene oxide/ $\mathrm{Fe}_{2} \mathrm{O}_{3}$ : all-solid-state $\mathrm{Z}$-scheme system for photocatalytic overall water splitting. Angew. Chem. Int. Ed. 58, 7102-7106 (2019).

27. Maeda, K., Murakami, N. \& Ohno, T. Dependence of activity of rutile titanium(IV) oxide powder for photocatalytic overall water splitting on structural properties. J. Phys. Chem. C. 118, 9093-9100 (2014).

28. Nakamura, R., Okamura, T., Ohashi, N., Imanishi, A. \& Nakato, Y. Molecular mechanisms of photo-induced oxygen evolution, PL emission, and surface roughening at atomically smooth (110) and (100) $\mathrm{n}-\mathrm{TiO}_{2}$ (rutile) surfaces in aqueous acidic solutions. J. Am. Chem. Soc. 127, 12975-12983 (2005).

29. Peng, S., Cao, Y., Zhou, F., Xu, Z. \& Li, Y. CoP decorated with $\mathrm{Co}_{3} \mathrm{O}_{4}$ as a cocatalyst for enhanced photocatalytic hydrogen evolution via dye sensitization. Appl. Surf. Sci. 487, 315-321 (2019).

30. Zhao, H., Guo, L., Xing, C., Liu, H. \& Li, X. A

homojunction-heterojunction-homojunction scaffold boosts photocatalytic $\mathrm{H} 2$ evolution over $\mathrm{Cd}_{0.5} \mathrm{Zn}_{0.5} \mathrm{~S} / \mathrm{CoO}$ hybrids. J. Mater. Chem. A 8, 1955-1965 (2020).

31. Liu, X., Min, S., Wang, F. \& Zhang, Z. Confining Mo-activated $\operatorname{CoS}_{x}$ active sites within MCM-41 for highly efficient dye-sensitized photocatalytic $\mathrm{H}_{2}$ evolution. J. Colloid Interf. Sci. 563, 112-121 (2020).

32. Tian, B. et al. Supported black phosphorus nanosheets as hydrogen-evolving photocatalyst achieving $5.4 \%$ energy conversion efficiency at $353 \mathrm{~K}$. Nat. Commun. 9, 1397 (2018).

33. Peng, R. et al. In-plane heterojunctions enable multiphasic two-dimensional (2D) $\mathrm{MoS}_{2}$ nanosheets as efficient photocatalysts for hydrogen evolution from water reduction. ACS Catal. 6, 6723-6729 (2016).

34. Vedhanarayanan, B., Chen, C. C. \& Lin, T. W. Plasmon-enhanced photocatalytic hydrogen production by dual dye sensitized ternary composite of $\mathrm{MoS}_{3} / \mathrm{Au}$ core-Ag shell nanoparticles/graphene. J. Power Sources 477, 229033 (2020).

35. Yu, F. et al. Molecular engineering of donor-acceptor conjugated polymer/g- $\mathrm{C}_{3} \mathrm{~N}_{4}$ heterostructures for significantly enhanced hydrogen evolution under visible-light irradiation. Adv. Funct. Mater. 28, 1804512 (2018).

36. Jing, $\mathrm{H}$. et al. Precursor-engineering coupled microwave molten-salt strategy enhances photocatalytic hydrogen evolution performance of $g-\mathrm{C}_{3} \mathrm{~N}_{4}$ nanostructures. ChemSusChem 13, 827-837 (2020).

37. Chen, J. et al. Molecular design of polymer heterojunctions for efficient solarhydrogen conversion. Adv. Mater. 29, 1606198 (2017).

38. Li, T. et al. Conductive polymer supported and confined iron phosphide nanocrystals for boosting the photocatalytic hydrogen production of graphitic carbon nitride. J. Mater. Chem. C. 8, 14540-14547 (2020). 
39. Yuan, W. et al. Laminated hybrid junction of sulfur-doped $\mathrm{TiO}_{2}$ and a carbon substrate derived from $\mathrm{Ti}_{3} \mathrm{C}_{2}$ MXenes: toward highly visible light-driven photocatalytic hydrogen evolution. Adv. Sci. 5, 1700870 (2018).

40. Xiao, S. et al. Copper nanowires: a substitute for noble metals to enhance photocatalytic $\mathrm{H}_{2}$ generation. Nano Lett. 15, 4853-4858 (2015).

41. Xiang, Y. et al. Enhanced visible light photocatalytic activity of $\mathrm{TiO}_{2}$ assisted by organic semiconductors: a structure optimization strategy of conjugated polymers. J. Mater. Chem. A 6, 153-159 (2018).

42. Xin, X. et al. In-situ growth of high-content $1 \mathrm{~T}$ phase $\mathrm{MoS}_{2}$ confined in the CuS nanoframe for efficient photocatalytic hydrogen evolution. Appl. Catal. BEnviron. 269, 118773 (2020).

43. Hong, Y. P. et al. Enhanced visible light photocatalytic hydrogen production activity of CuS/ZnS nanoflower spheres. J. Mater. Chem. A 3, 13913-13919 (2015).

44. Yu, S. et al. Efficient photocatalytic hydrogen evolution with ligand engineered all-inorganic InP and InP/ZnS colloidal quantum dots. Nat. Commun. 9, 4009 (2018).

45. Kosco, J. et al. Enhanced photocatalytic hydrogen evolution from organic semiconductor heterojunction nanoparticles. Nat. Mater. 19, 559-565 (2020).

46. Li, Z. et al. Two-dimensional Janus heterostructures for superior Z-scheme photocatalytic water splitting. Nano Energy 59, 537-544 (2019).

47. Zhang, F. M. et al. Rational design of MOF/COF hybrid materials for photocatalytic $\mathrm{H}_{2}$ evolution in the presence of sacrificial electron donors. Angew. Chem. Int. Ed. 57, 12106-12110 (2018).

48. Wang, X. et al. Sulfone-containing covalent organic frameworks for photocatalytic hydrogen evolution from water. Nat. Chem. 10, 1180-1189 (2018).

49. Ran, J. et al. 2D metal organic framework nanosheet: a universal platform promoting highly efficient visible-light-induced hydrogen production. $A d v$. Energy Mater. 9, 1803402 (2019).

50. Xing, M. et al. Spatially separated CdS shells exposed with reduction surfaces for enhancing photocatalytic hydrogen evolution. Adv. Funct. Mater. 27, 1702624 (2017).

51. $\mathrm{Lu}, \mathrm{Y}$. et al. Hierarchical $\mathrm{CdS} / \mathrm{m}-\mathrm{TiO}_{2} / \mathrm{G}$ ternary photocatalyst for highly active visible light-induced hydrogen production from water splitting with high stability. Nano Energy 47, 8-17 (2018).

52. Lee, B. H. et al. Reversible and cooperative photoactivation of single-atom $\mathrm{Cu} /$ $\mathrm{TiO}_{2}$ photocatalysts. Nat. Mater. 18, 620-626 (2019).

53. Yu, Y. et al. Surface engineering for extremely enhanced charge separation and photocatalytic hydrogen evolution on $\mathrm{g}_{-} \mathrm{C}_{3} \mathrm{~N}_{4}$. Adv. Mater. 30, 1705060 (2018).

54. Meng, N. et al. Engineering oxygen-containing and amino groups into twodimensional atomically-thin porous polymeric carbon nitrogen for enhanced photocatalytic hydrogen production. Energy Environ. Sci. 11, 566-571 (2018).

55. Zhang, Y. et al. Leaf-mosaic-inspired vine-like graphitic carbon nitride showing high light absorption and efficient photocatalytic hydrogen evolution. Adv. Energy Mater. 8, 1801139 (2018).

56. Zhang, L. et al. Localized surface plasmon resonance enhanced photocatalytic hydrogen evolution via Pt@Au NRs/ $\mathrm{C}_{3} \mathrm{~N}_{4}$ nanotubes under visible-light irradiation. Adv. Funct. Mater. 29, 1806774 (2019).

57. Li, Q. Y. \& Lu, G. X. Significant effect of pressure on the $\mathrm{H}_{2}$ releasing from photothermal-catalytic water steam splitting over $\mathrm{TiSi}_{2}$ and $\mathrm{Pt} / \mathrm{TiO}_{2}$. Catal. Lett. 125, 376-379 (2008).

58. Domen, K., Naito, S., Soma, M., Onishi, T. \& Tamaru, K. Photocatalytic decomposition of water-vapor on an $\mathrm{NiO}_{-} \mathrm{SrTiO}_{3}$ catalyst. J. Chem. Soc. Chem. Comm. 12, 543-544 (1980)

59. Ni, G. et al. A salt-rejecting floating solar still for low-cost desalination. Energy Environ. Sci. 11, 1510-1519 (2018)

60. Wang, Y. et al. Linker-controlled polymeric photocatalyst for highly efficient hydrogen evolution from water. Energy Environ. Sci. 10, 1643-1651 (2017).

61. Baga, A. N., Johnson, G. R. A., Nazhat, N. B. \& Saadalla-nazhat, R. A. A simple spectrophotometric determination of hydrogen peroxide at low concentrations in aqueous solution. Anal. Chim. Acta 204, 349-353 (1988).

62. Blöchl, P. E. Projector augmented-wave method. Phys. Rev. B 50, 17953-17979 (1994).

63. Rossmeisl, J., Logadottir, A. \& Norskov, J. K. Electrolysis of water on (oxidized) metal surfaces. Chem. Phys. 319, 178-184 (2005).

64. Norskov, J. K. et al. Origin of the overpotential for oxygen reduction at a fuelcell cathode. J. Phys. Chem. B 108, 17886-17892 (2004).
65. Liu, X., Jiao, Y., Zheng, Y., Davey, K. \& Qiao, S. Z. A computational study on $\mathrm{Pt}$ and $\mathrm{Ru}$ dimers supported on graphene for the hydrogen evolution reaction: new insight into the alkaline mechanism. J. Mater. Chem. A 7, 3648-3654 (2019).

66. Jiao, Y., Zheng, Y., Davey, K. \& Qiao, S. Z. Activity origin and catalyst design principles for electrocatalytic hydrogen evolution on heteroatom-doped graphene. Nat. Energy 1, 16130-16138 (2016).

67. Zhang, C. et al. Sub-1.1 nm ultrathin porous CoP nanosheets with dominant reactive $\{200\}$ facets: a high mass activity and efficient electrocatalyst for the hydrogen evolution reaction. Chem. Sci. 8, 2769-2775 (2017).

68. Mathew, K., Sundararaman, R., Letchworth-Weaver, K., Arias, T. A. \& Hennig, R. G. Implicit solvation model for density-functional study of nanocrystal surfaces and reaction pathways. J. Chem. Phys. 140, 084106 (2014).

69. Mathew, K., Kolluru, V. S. C., Mula, S., Steinmann, S. N. \& Hennig, R. G. Implicit self-consistent electrolyte model in plane-wave density-functional theory. J. Chem. Phys. 151, 234101 (2019).

70. Lide, D. R. Handbook of Chemistry and Physics (CRC Press, 2004).

\section{Acknowledgements}

This research is supported by the Basic Research Fund for Free Exploration in Shenzhen (Grant No. JCYJ20180306171402878), the project of Shaanxi Young Stars in Science and Technology (2017KJXX-18), the Shaanxi International Cooperation Project (2020KWZ-018), and the Fundamental Research Funds for the Central Universities (3102019ghxm003, 3102019JC005, 3102019ghjd001). We thank the members from the Analytical \& Testing Center of Northwestern Polytechnical University for the help of TEM and XPS characterization. We also thank Prof. Weihong Qi, Prof. Qingfeng Zeng, and Prof. Junjie Wang for valuable discussion about the theoretical calculation.

\section{Author contributions}

B.W. and X.L. conceived the concept and directed the research. S.G. and X.L. designed the project. S.G. carried out material synthesis and related characterization tests. J.L. gave advice on the experiments. S.G., X.L., and B.W. wrote the paper. All authors discussed the results and commented on the paper.

\section{Competing interests}

The authors declare no competing interests.

\section{Additional information}

Supplementary information The online version contains supplementary material available at https://doi.org/10.1038/s41467-021-21526-4.

Correspondence and requests for materials should be addressed to X.L. or B.W.

Peer review information Nature Communications thanks Harald Oberhofer for their contributions to the peer review of this work. Peer review reports are available.

Reprints and permission information is available at http://www.nature.com/reprints

Publisher's note Springer Nature remains neutral with regard to jurisdictional claims in published maps and institutional affiliations.

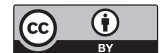

Open Access This article is licensed under a Creative Commons Attribution 4.0 International License, which permits use, sharing, adaptation, distribution and reproduction in any medium or format, as long as you give appropriate credit to the original author(s) and the source, provide a link to the Creative Commons license, and indicate if changes were made. The images or other third party material in this article are included in the article's Creative Commons license, unless indicated otherwise in a credit line to the material. If material is not included in the article's Creative Commons license and your intended use is not permitted by statutory regulation or exceeds the permitted use, you will need to obtain permission directly from the copyright holder. To view a copy of this license, visit http://creativecommons.org/ licenses/by/4.0/.

(C) The Author(s) 2021 